\title{
INFLUENCE OF GAS SHIELDING CONDITIONS UPON THE THERMAL PROCESSES IN WELD JOINTS WHEN WELDING WITH A CONSUMABLE ELECTRODE
}

\author{
Dr. D.A. Chinakhov
}

\author{
Yurga Institute of Technology (branch) of Tomsk Polytechnic University \\ 652055, Leningradskaya st., 26, Yurga, Russia, tel./fax+7(384-51)6-53-95, chinakhov@tpu.ru
}

\begin{abstract}
The author has studied the dependence of changes in heat distribution in steel 30HGSA weld joints upon the gas shielding conditions. It has been established that under the double-jet gas shielding the rate of temperature saturation in the welded plates is a little higher and temperatures of weld metal and the heat-affected area equalize by $1 \ldots 1.4$ seconds earlier than it happens under the traditional single-jet shielding. The developed redetermined formula for calculation heat distribution in the process of automatic single-pass welding of plates under the double-jet gas shield conditions allows to estimate the thermal cycle of a point with an error of less than $10 \%$.
\end{abstract}

Key words: welding with a consumable electrode, heat distribution, gas shield, welding thermal cycle.

The majority of welding processes suppose heating the component parts by various heat sources. In fusion welding the weld joint quality is determined by the heating and cooling conditions. The history of a thermal process determines the melting productivity of the basic and adding material, the direction and completeness of the metallurgical processes in the weld pool, conditions of the joint and the heat-affected area metal formation, as well as the running ability of the weld joints [1].

Control of the thermal cycle in the joint material is one of the main tasks of modern welding production. Theoretical and experimental study of heat and mass transfer phenomena have large practical value as well as the study of complex physical-chemical processes and structural-phase transformations which take place in the process of welding while heating and cooling the workpieces. The theory of welding processes in our country (Russia) and abroad pays much attention to the problem of estimation of thermal fields and cooling rates which are important for the hardened steels welding.

Modern theories and works [1-4] considering welding thermal processes and formulating basic laws and notions of thermal field distribution do not take a number of significant factors into consideration, i.e. heat exchange with the environment, welding method and other. The calculations often contain composite functions. It increases the calculation time, involving complicated mathematical apparatus and computing machinery. Besides, the calculated data often differ from the practical results.

The most accurate and adequate description of the thermal processes can be made by the results of experimental study of the thermal fields distribution. The experimental picture of the thermal field distribution can be received by thermocouple or by thermal imaging equipment.

Formation of structure and phase state of metal depends on its chemical composition and heating conditions [112]. The welding thermal cycle and the cooling rate determine the structural-phase state of the heat-affected area of hardened steels [2, 5-7, 13 and other].

In order to study the dependence of changes in thermal cycle and cooling rate of steel 30HGSA weld joints upon the gas shielding conditions when fusion welding we have carried out a number of experiments using modern thermal imaging equipment.

We completed machine welding of steel 30HGSA plates $300 \times 150 \mathrm{~mm} 8 \mathrm{~mm}$ thick in $\mathrm{CO}_{2}$ with Sv-08G2S electrode $1.2 \mathrm{~mm}$ in diameter. The samples were welded with the application of the developed welding method (doublejet shielding) and traditional method (single-jet shielding) under the following conditions: welding current $\mathrm{I}=190 \mathrm{~A}$, welding speed $V=27 \ldots 28 \mathrm{~cm} / \mathrm{min}$, shielding gas flow rate $Q=17 \mathrm{l} / \mathrm{min}$, stick-out distance $\mathrm{L}=12 \mathrm{~mm}$, arc voltage $U=27$ V. Welding rectifier VSG-303 was applied as the power source. Field logging was performed by a thermal imager ThermaCAM P65HS produced by FLIR. The recording was carried out while completing one pass (60 s) and $60 \mathrm{~s}$ after completing the pass, frame frequency being 5 frames per second [14-16]. As a result we received the thermal field images (thermograms) of the heating and cooling processes in the welded item. 


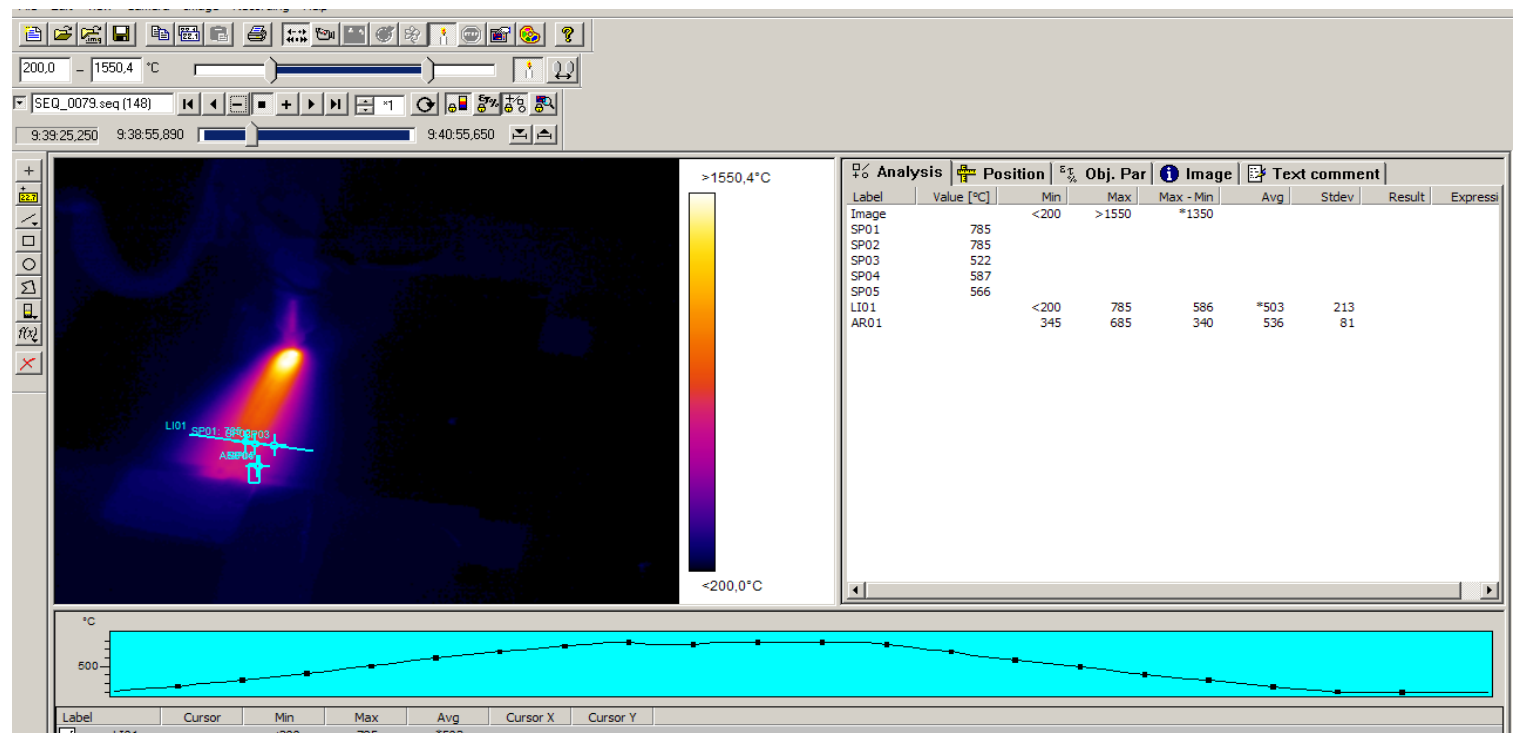

a)

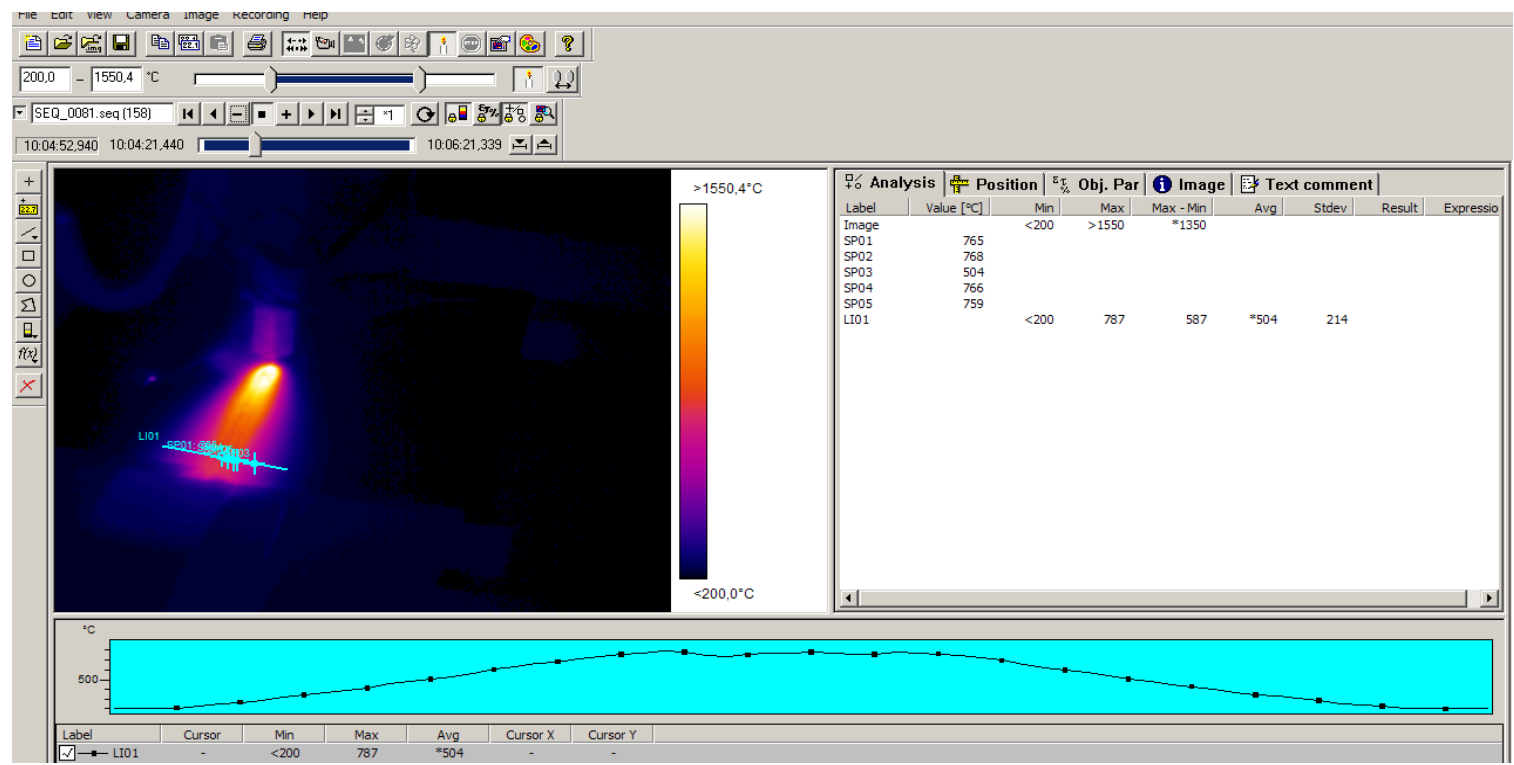

b)

Fig.1. The thermogram of the welding process (heating): a) double-jet gas shielding(079), b) traditional gas shielding (081)

The thermograms were used to draw thermal cycles for three points situated at the distance of $10 \mathrm{~mm}$ from the welded plates edges (butt-to-butt without grooving) - along $X$ : along the weld joint centre $Y=0 \mathrm{~cm}$, at the distance of $Y=0.5$ $\mathrm{cm}$ from the weld joint center and $Y=1.4 \mathrm{~cm}$ from the weld joint center. The temperature changes in the given points are shown in tables 1 and 2, cycle schedules are given in Figure 2. 
Table 1. Temperature changes in points $Y=0 \mathrm{~cm}, Y=0.5 \mathrm{~cm}, \mathrm{Y}=1.4 \mathrm{~cm}$ from the weld center when welding in $\mathrm{CO}_{2}$ with double-jet gas shielding

\begin{tabular}{|c|c|c|c|c|}
\hline \multirow[b]{2}{*}{ Time, s } & \multicolumn{3}{|c|}{ Temperature, ${ }^{\circ} \mathrm{C}$} & \multirow[b]{2}{*}{ Note } \\
\hline & Weld joint center & $\begin{array}{l}0.5 \mathrm{~cm} \text { from the weld } \\
\text { joint center }\end{array}$ & $\begin{array}{l}1.4 \mathrm{~cm} \text { from the weld } \\
\text { joint center }\end{array}$ & \\
\hline 0,00 & 20,00 & 20,00 & 20,00 & Start welding \\
\hline 1,00 & 323,00 & 20,00 & 20,00 & \\
\hline 3,00 & 1600,00 & 937,00 & 20,00 & \\
\hline 4,90 & 1800,00 & 1516,00 & 20,00 & \\
\hline 6,90 & 1800,00 & 1412,00 & 206,00 & \\
\hline 9,88 & 1600,00 & 1259,00 & 335,00 & \\
\hline 10,88 & 1442,00 & 1209,00 & 373,00 & \\
\hline 14,88 & 1143,00 & 1053,00 & 462,00 & \\
\hline 15,88 & 1100,00 & 1020,00 & 481,00 & \\
\hline 20,88 & 974,00 & 914,00 & 512,00 & \\
\hline 26,00 & 852,00 & 836,00 & 527,00 & \\
\hline 28,36 & 803,00 & 799,00 & 528,00 & \multirow{3}{*}{$\begin{array}{c}\text { Temperature saturation } \\
\text { (equalizing) area }\end{array}$} \\
\hline 29,36 & 785,00 & 785,00 & 522,00 & \\
\hline 30,36 & 769 & 772 & 524 & \\
\hline 32,68 & 732 & 743 & 521 & \\
\hline 45,88 & 596 & 622 & 488 & \\
\hline 53,88 & 550 & 574 & 466 & \\
\hline 63,08 & 503 & 529 & 442 & Finish welding \\
\hline 69,08 & 478 & 505 & 427 & \\
\hline 75 & 449 & 462 & 380 & \\
\hline 103 & 371 & 390 & 337 & \\
\hline 120 & 339 & 355 & 309 & \\
\hline
\end{tabular}

Table 2. Temperature changes in points $Y=0 \mathrm{~cm}, Y=0.5 \mathrm{~cm}, Y=1.4 \mathrm{~cm}$ from the weld center when welding in $\mathrm{CO}_{2}$ with traditional (single-jet) gas shielding

\begin{tabular}{|c|c|c|c|c|}
\hline \multirow{2}{*}{ Time, s } & \multicolumn{3}{|c|}{ Temperature, ${ }^{\circ} \mathrm{C}$} & \multirow{2}{*}{ Note } \\
\cline { 2 - 4 } & Weld joint center & $\begin{array}{c}0.5 \mathrm{~cm} \text { from the weld } \\
\text { joint center }\end{array}$ & $\begin{array}{c}1.4 \mathrm{~cm} \text { from the weld } \\
\text { joint center }\end{array}$ & Start welding \\
\hline 0,00 & 20,00 & 20,00 & 20,00 & \\
\hline 1,00 & 598,00 & 432,00 & 20,00 & \\
\hline 2,00 & 1600,00 & 850,00 & 20,00 & \\
\hline 3,00 & 1800,00 & 1200,00 & 20,00 & \\
\hline 4,96 & 1800,00 & 1487,00 & 20,00 & \\
\hline 7,96 & 1800,00 & 1278,00 & 231,00 & \\
\hline 8,96 & 1600,00 & 1215,00 & 230,00 & \\
\hline 9,96 & 1537,00 & 1185,00 & 259,00 & \\
\hline 15,18 & 1131,00 & 1034,00 & 403,00 & \\
\hline 16,18 & 1076,00 & 1017,00 & 434,00 & \\
\hline 19,16 & 986,00 & 938,00 & 451,00 & \multirow{2}{*}{ Temperature saturation } \\
\hline 25,12 & 877,00 & 849,00 & 484,00 & \\
\hline 29,10 & 809,00 & 797,00 & 483,00 & \\
\hline 30,50 & 787,00 & 782,00 & 484,00 & \\
\hline 31,50 & 765,00 & 768,00 & 754,00 & \\
\hline 32,34 & 754 & 756 & 497 & \\
\hline
\end{tabular}




\begin{tabular}{|c|c|c|c|c|}
\hline 34,1 & 732 & 742 & 491 & \\
\hline 47,18 & 603 & 628 & 458 & \\
\hline 54,44 & 555 & 579 & 464 & \\
\hline 65,1 & 504 & 526 & 444 & Finish welding \\
\hline 79,33 & 460 & 485 & 387 & \\
\hline 94,1 & 415 & 440 & 363 & \\
\hline 120 & 353 & 378 & 341 & \\
\hline
\end{tabular}

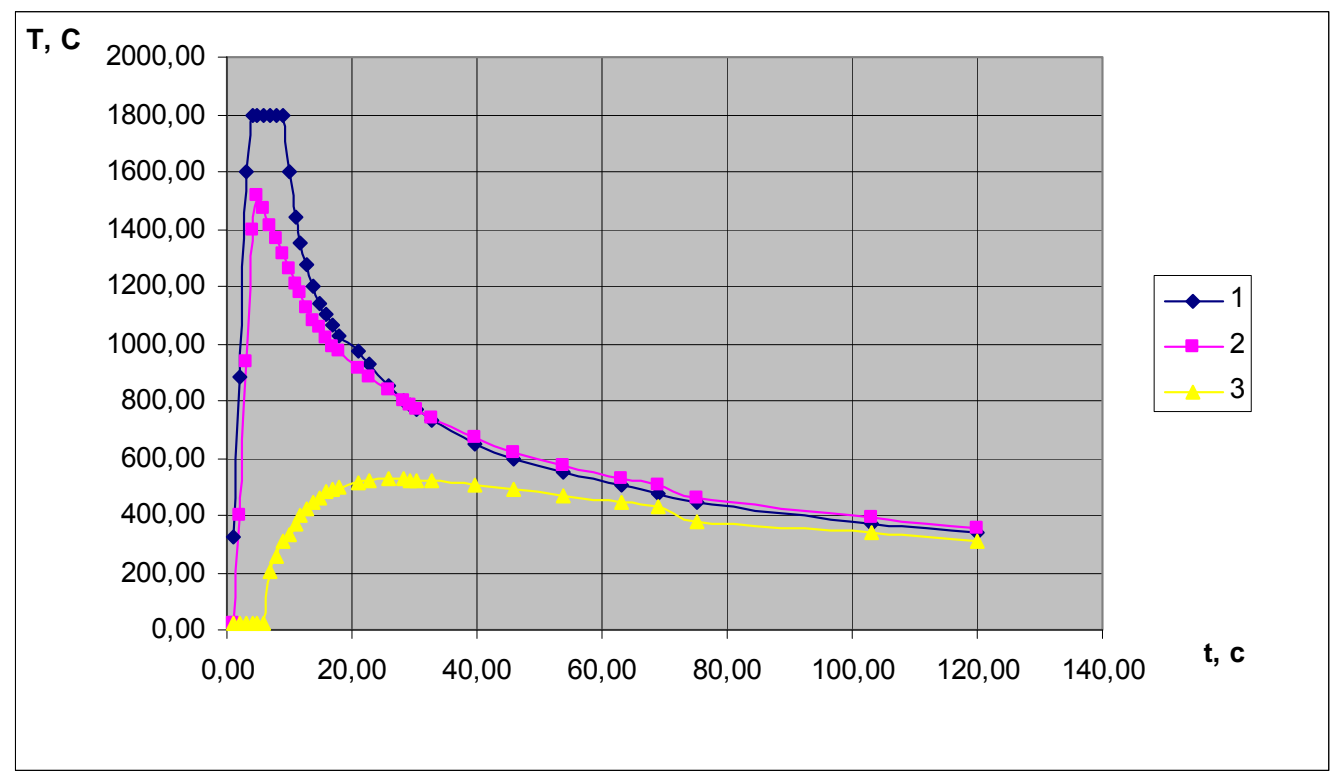

a)

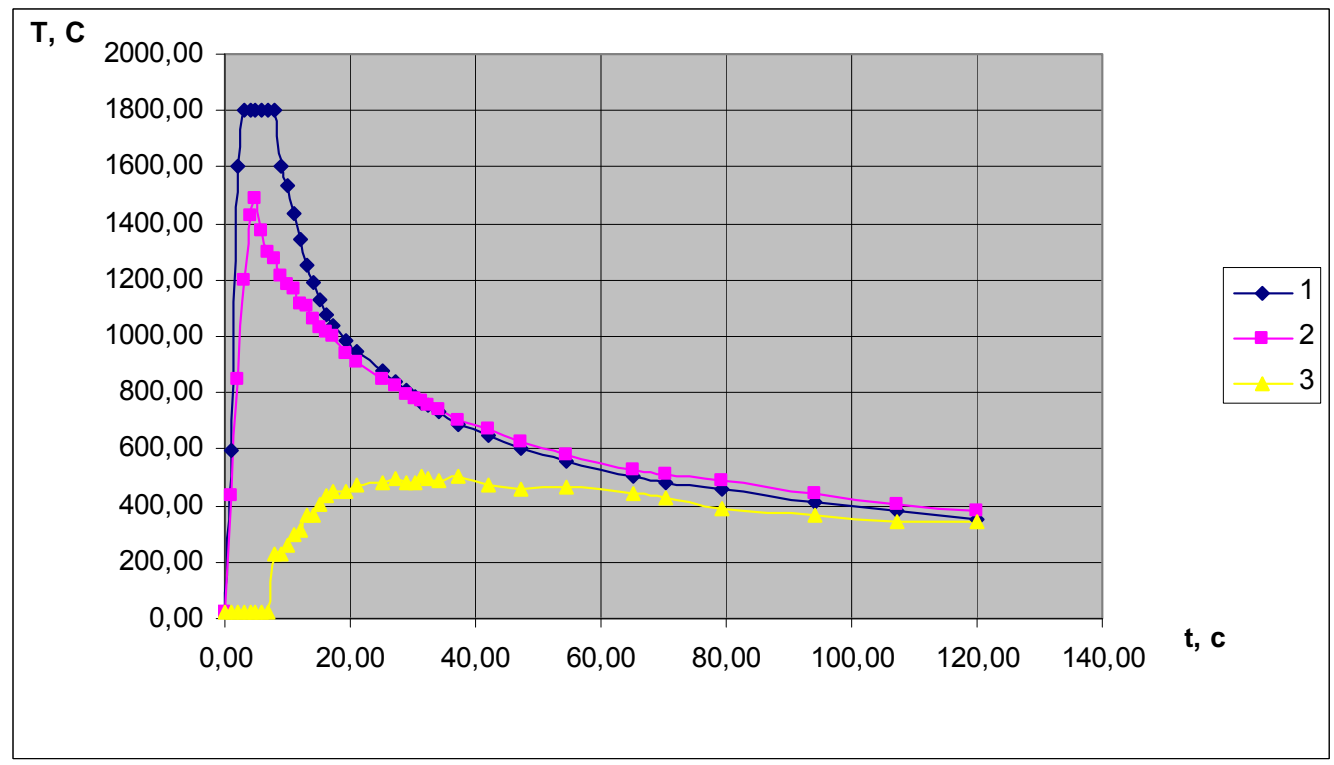

b)

Fig. 2. Thermal cycles for $Y=0 \mathrm{~cm}$ (Line 1), $Y=0.5 \mathrm{~cm}$ (Line 2), $Y=1.4 \mathrm{~cm}$ (Line 3) from the weld center when welding in $\mathrm{CO}_{2}$ : a) with double-jet gas shielding, b) with traditional gas shielding 
The analysis of the experimental data showed that the thermal cycles of the weld metal and the heat-affected area metal are different, the temperatures equalize at $785^{\circ} \mathrm{C}$ and the weld metal which previously was hotter becomes cooler as compared to the metal of the heat-affected area under any type of gas shielding applied. The rate of temperature saturation in the welded plates under the double-jet gas shielding is a little higher and temperatures of weld metal and heat-affected area metal equalize by $1 . .1 .4$ seconds earlier than it happens under the traditional single-jet shielding. The temperature in front of the heat source increases more rapidly under the traditional single-jet gas shielding.

We used the experimentally obtained thermal cycles and temperature values for the three chosen points $Y=0$ $\mathrm{cm}, \mathrm{Y}=0.5 \mathrm{~cm}, \mathrm{Y}=1.4 \mathrm{~cm}$ from the weld joint center to calculate the cooling rates. To make the cooling rates analysis more convenient we divided the studied temperature interval into the three groups according to the temperatures of structural-phase transformations:

1. from 1600 to $1100^{\circ} \mathrm{C}$;

2. from 1100 to $740{ }^{\circ} \mathrm{C}$;

3. from 740 to $500{ }^{\circ} \mathrm{C}$ (end of welding).

We calculated the linear cooling rate for every temperature group $\left({ }^{\circ} \mathrm{C} / \mathrm{s}\right)$ using the formula:

$$
\omega=\frac{T \max -T \min }{t \min -t \max },
$$

where Tmax and Tmin - maximum and minimum temperature values in the given temperature group; tmax and tmin time for reaching the maximum and minimum temperatures in the given temperature group for the given point.

The values of the cooling rates $\omega\left({ }^{\circ} \mathrm{C} / \mathrm{s}\right)$ for the three chosen points $Y=0 \mathrm{~cm}, Y=0.5 \mathrm{~cm}, \mathrm{Y}=1.4 \mathrm{~cm}$ from the weld joint center depending on the type of gas shielding are shown in Table 3.

Table 3. Comparing the cooling rates $\omega\left({ }^{\circ} \mathrm{C} / \mathrm{s}\right)$ for $Y=0 \mathrm{~cm}, Y=0.5 \mathrm{~cm}, Y=1.4 \mathrm{~cm}$ from the weld center when welding in $\mathrm{CO}_{2}$ with double-jet and with traditional (single-jet) gas shielding

\begin{tabular}{|c|c|c|c|c|}
\hline \multirow{2}{*}{ The welding method } & \multirow{2}{*}{ Temperature interval, ${ }^{\circ} \mathrm{C}$} & \multicolumn{3}{|c|}{ Cooling rate $\omega,{ }^{\circ} \mathrm{C} / \mathrm{s}$} \\
\cline { 3 - 5 } & & $\begin{array}{c}\text { Weld joint } \\
\text { center }\end{array}$ & $\begin{array}{c}0.5 \mathrm{~cm} \text { from the } \\
\text { weld joint center }\end{array}$ & $\begin{array}{c}1.4 \mathrm{~cm} \text { from the } \\
\text { weld joint center }\end{array}$ \\
\hline \multirow{3}{*}{ Double-jet gas shielding } & $1600-1100$ & 83,3 & 49,4 & - \\
\cline { 2 - 5 } & $1100-740$ & 21,9 & 19,1 & - \\
\cline { 2 - 5 } & $740-500$ & 7,5 & 7 & - \\
\hline \multirow{3}{*}{ Traditional gas shielding } & $1600-1100$ & 72,6 & 47,5 & - \\
\cline { 2 - 5 } & $1100-740$ & 19,2 & 17,3 & 2 \\
\cline { 2 - 5 } & $740-500$ & 7,3 & 6,2 & -5 \\
\hline
\end{tabular}

To compare the experimentally obtained thermal cycles and cooling rates with their values obtained due to the widely used formulas [1-4] we carried out a number of calculations.

The calculation of heat conduction under automatic single-pass welding [2] was completed according to the following formula:

$$
T(y, t)=\frac{q \cdot e^{-\frac{y^{2}}{4 a t}}}{v \delta c p \sqrt{4 \pi a t}}
$$

where $\alpha=0.8 \mathrm{~cm}^{2} / \mathrm{s}$ - heat-transfer coefficient; $\delta=0.8 \mathrm{~cm}$ - thickness of the welded plates; $v=0,46 \mathrm{~cm} / \mathrm{s}-$ welding rate; $q-$ actual arc power which is calculated by Eq. $3 ; \mathrm{t}-$ time counted from the moment of arc passing the plane where the studied point is placed, $\mathrm{s} ; \mathrm{y}$ - the distance measured perpendicularly from the weld joint axis in the horizontal plane $(0$; $0.5 ; 1.4), \mathrm{cm} ; \mathrm{c} \rho=5 \mathrm{~J} /\left(\mathrm{sm}^{3}\right.$ * degree $)$ - volumetric heat capacity.

$$
q=\eta U I
$$

where $\eta=0.8$ - effective efficiency of the item heating; $U=27 \mathrm{~V}-$ arc voltage; I=190A - welding current.

The diagrams of the thermal cycles calculated according to Eq. 2 are presented at Figure 3. 


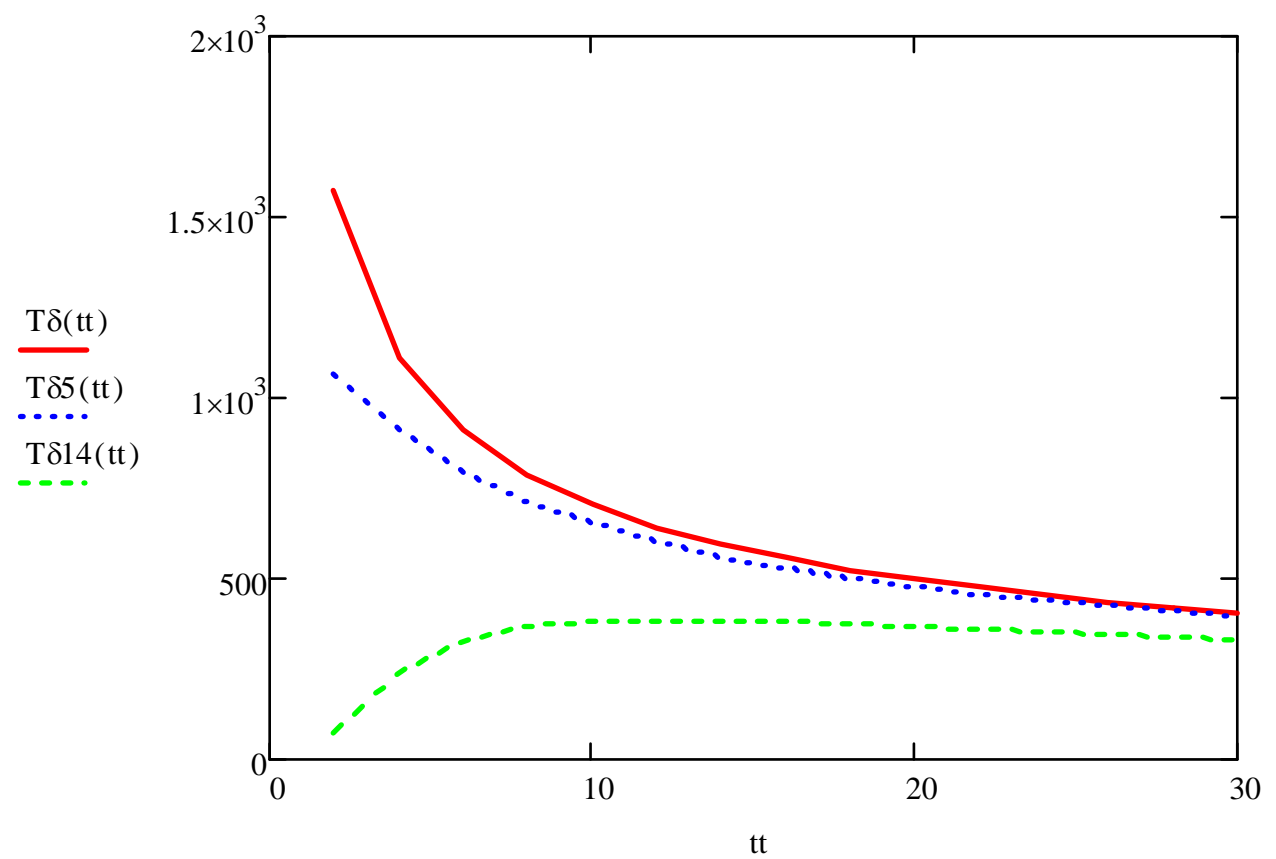

Fig. 3. Thermal cycles in $Y=0 \mathrm{~cm}, Y=0.5 \mathrm{~cm}, Y=1.4 \mathrm{~cm}$, calculated according to the Eq. 2

The analysis of the experimentally obtained and calculated by Eq. 2 thermal cycles showed that they almost match each other in terms of quality but the time distribution of calculated values is four times smaller.

Basing on the experimental results and theoretical study of the thermal cycles for fusion-welding in $\mathrm{CO}_{2}$ we developed an improved formula for calculating heat distribution for automatic single-pass welding under double-jet shielding:

$$
T(y, t)=\frac{q \cdot e^{-\frac{y^{2}}{4 a t}}}{v \delta c p \sqrt{\left(4+\theta^{2}\right) a\left(t+\frac{y}{v}\right)}},
$$

where $\theta$ - nondimensional quantity equal to the distance $y(\mathrm{~cm})$ of the chosen point.

The calculated temperature values in the given points $Y=0 \mathrm{~cm}, Y=0.5 \mathrm{~cm}, Y=1.4 \mathrm{~cm}$ from the weld center are shown in Table 4. The relative miscalculation for the developed improved Eq. 4 as compared to the experimental data does not exceed $10 \%$ for $Y=0 \mathrm{~cm}, Y=0.5 \mathrm{~cm}$. The calculated values for $Y=1.4 \mathrm{~cm}$ should be 20 seconds shifted along the time scale so that they better match the experimental data.

Table 4. Calculated temperature values in $Y=0 \mathrm{~cm}, Y=0.5 \mathrm{~cm}, Y=1.4 \mathrm{~cm}$ from the weld joint center, according to the developed Eq.4

\begin{tabular}{|c|c|c|c|c|}
\hline \multirow{2}{*}{ Time, s } & \multicolumn{4}{|c|}{ Temperature, ${ }^{\circ} \mathrm{C}$} \\
\cline { 2 - 5 } & Weld joint center & $\begin{array}{c}0.5 \mathrm{~cm} \text { from the weld } \\
\text { joint center }\end{array}$ & $\begin{array}{c}1.4 \mathrm{~cm} \text { from the weld } \\
\text { joint center }\end{array}$ & $\begin{array}{c}1.4 \mathrm{~cm} \text { from the weld } \\
\text { joint center with } 20 \\
\text { second shift }\end{array}$ \\
\hline 1 & 3943 & 1212 & - & - \\
\hline 2 & 2788 & 1473 & 67 & - \\
\hline 4 & 1971 & 1395 & 263 & - \\
\hline 5 & 1763 & 1326 & 335 & - \\
\hline 15 & 1018 & 905 & 505 & 335 \\
\hline 25 & 789 & 726 & 477 & 505 \\
\hline 35 & 667 & 623 & 440 & 440 \\
\hline 55 & 532 & 504 & 379 & 379 \\
\hline 75 & 455 & 434 & 337 & 337 \\
\hline 95 & 405 & 387 & 306 & 306 \\
\hline 115 & 368 & 353 & 282 & \\
\hline
\end{tabular}


Calculation of the cooling rates $\omega\left({ }^{\circ} \mathrm{C} / \mathrm{s}\right)$ in the chosen points was completed using a well-known Eq.5, the author recommends to estimate the instantaneous cooling rate only for the weld axis due to its insignificant difference with the cooling rate of the heat-affected area [17] and the linear cooling rate Eq. 1 using the temperature values obtained from the developed improved Eq. 4. The results of the calculations are presented in Table 5.

$$
\omega=\frac{-2 \pi \lambda\left(T-T_{H}\right)}{q / v},
$$

where $\lambda=0.4 \mathrm{Watt} /(\mathrm{cm} \cdot$ degree $)-$ heat conductivity coefficient.

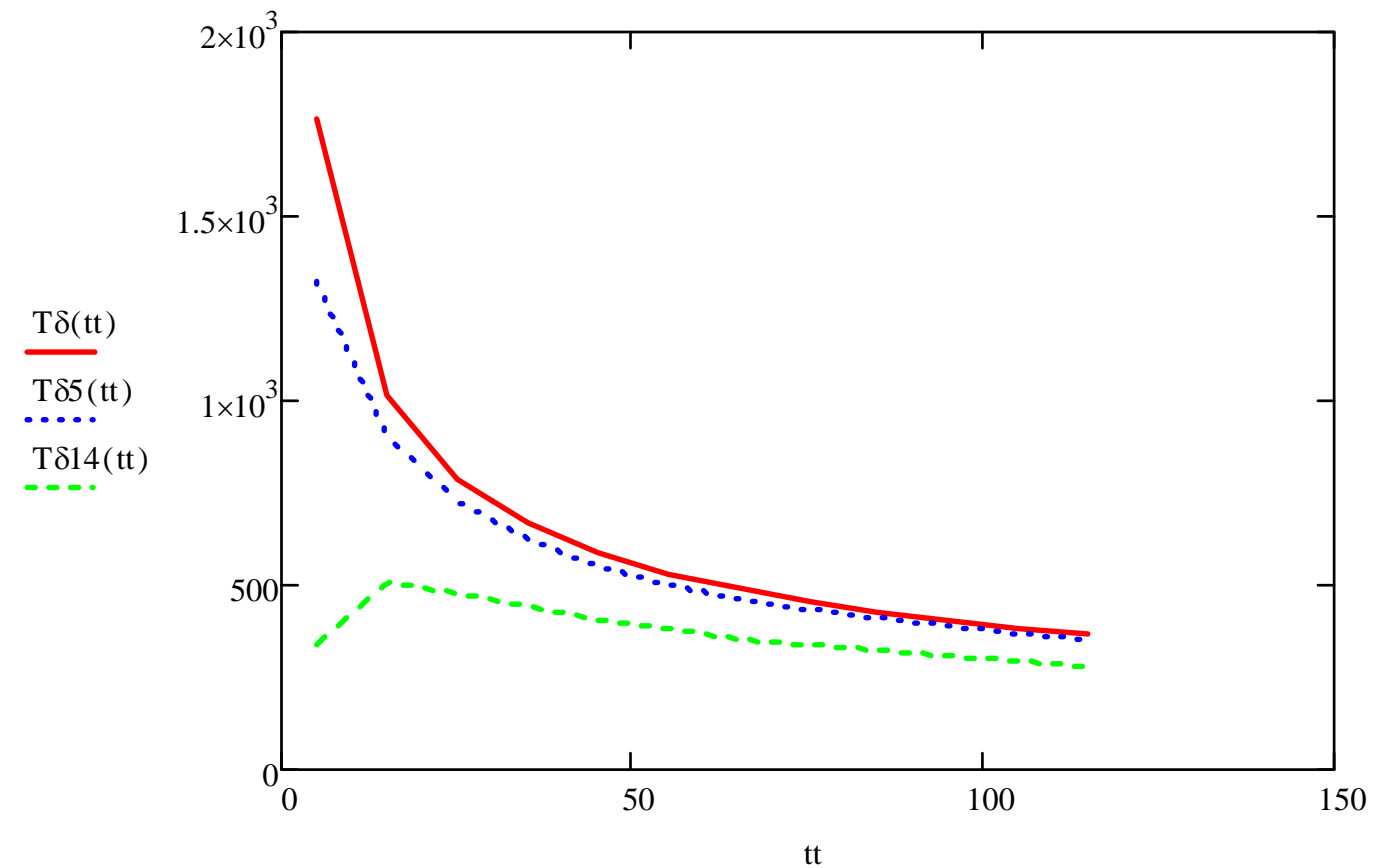

Fig. 4. Thermal cycles in $Y=0 \mathrm{~cm}, Y=0.5 \mathrm{~cm}, Y=1.4 \mathrm{~cm}$, calculated according to Eq. 4

Table 5. Comparing the calculated cooling rates $\omega\left({ }^{\circ} \mathrm{C} / \mathrm{s}\right)$

\begin{tabular}{|c|c|c|c|c|}
\hline \multirow[b]{2}{*}{ Name } & \multirow{2}{*}{$\begin{array}{l}\text { Temperature interval, } \\
{ }^{\circ} \mathrm{C}\end{array}$} & \multicolumn{3}{|c|}{ Скорость охлаждения $\omega,{ }^{\circ} \mathrm{C} / \mathrm{s}$} \\
\hline & & weld center & $\begin{array}{l}0.5 \mathrm{~cm} \text { from the } \\
\text { weld center }\end{array}$ & $\begin{array}{c}1.4 \mathrm{~cm} \text { from the } \\
\text { weld center }\end{array}$ \\
\hline \multirow{3}{*}{ Eq. 5} & $1600-1100$ & 70,4 & - & - \\
\hline & $1100-740$ & 36,5 & - & - \\
\hline & $740-500$ & 16,2 & - & - \\
\hline \multirow{3}{*}{$\begin{array}{c}\omega \text { according to Eq. } 1 \text { for } \\
\text { temperatures calculated by } \\
\text { Eq. } 4\end{array}$} & $1600-1100$ & 73,7 & 52,7 & - \\
\hline & $1100-740$ & 22,6 & 23,6 & - \\
\hline & $740-500$ & 7,0 & 7,3 & 2,8 \\
\hline
\end{tabular}

The values of the cooling rates obtained during the study can be compared to M.H. Shorshorov's results [5], where he gives the optimal interval of the heat-affected area cooling rates for steel 30HGSA single-pass welding being equal $1.6-8.0^{\circ} \mathrm{C} / \mathrm{s}$. The values of the cooling rates received experimentally and calculated according to Eq. 1 with the application of temperature values received by the developed and redetermined Eq. 4 do not contradict the experimental data of other authors [5-7, 18 and other].

It has been estimated that the thermal cycles of the weld metal and the heat-affected area metal of the weld joints are different, the temperatures equalize at $785^{\circ} \mathrm{C}$ and the weld metal which previously was hotter becomes cooler as compared to the metal of the heat-affected area under any type of gas shielding applied. The rate of temperature saturation under the double-jet gas shielding is a little higher and temperatures of weld metal and the heat-affected area equalize by $1 \ldots 1.4$ seconds earlier than it happens under the traditional single-jet shielding. The developed redetermined formula for calculation heat distribution in the process of automatic single-pass welding of plates under the double-jet gas shield conditions allows to estimate the thermal cycle of a point with an error of less than $10 \%$. 
References

[1] Frolov V.V. The welding processes theory. M.: Higher school. - 1988. -559 p.

[2] Bagryansky K.V., Dobrotina Z.A., Khrenov K.K. The welding processes theory. Kiev: "Vischa shkola". - 1976. - 424p.

[3] Rykalin N.N. Thermal processes calculations when welding. - M.: Mashgiz. - 1951. - 296 p.

[4] Berezovsky B.M. Mathematical models of arc welding: in 7 volumes. Vol. 4. Principles of thermal processes in the welded units. - Chelyabinsk: The South Urals State University press, 2006. $-547 p$.

[5] Shorshorov M.H. Metallurgy of steel and titanium alloys welding. M.: Science. - 1965. - $337 \mathrm{p}$.

[6] Livshits L.S., Khakimov A.N. Welding metallurgy and thermal treatment of the weld joints. $-2^{\text {nd }}$ edition, changed and improved. M.: Engineering. - 1989. - 339p.

[7] Lakhtin Y.M. Metallurgy and thermal treatment of metals. - 3d edition, changed and improved. M.: Metallurgy. 1983. $-359 \mathrm{p}$.

[8] Welding and welded materials: in 3 volumes. Vol. 1. Welding characteristics of materials: reference issue/under the edition of E.L. Makarov. - M.: Metallurgy, $1991-528$ p.

[9] Potapyevsky A.G. Welding with a consumable electrode under gas shielding. M.: Engineering, 1974. - 240 p.

[10] Lenivkin V.A., Dyurgerov N.G., Sagirov Kh.N. Technological properties of the weld arc under gas shielding. M.: Engineering, 1989. - $264 \mathrm{p}$.

[11] Stolbov V.P. Weld pool: Monography. - Tolyatti: TSU, 2007. - 147 p.

[12] Chinakhov D.A. Influence of fusion welding conditions upon the structure and properties of hardened steels joints: monography / D.A. Chinakhov. Yurga Institute of Technology. - Tomsk: Tomsk Polytechnic University Press, 2010. - 114 p.

[13] Lakhtin Yu.M., Leontyeva V.P. Materials science: course book for higher technical school. - 3d edition, changed and improved. - M.: Engineering, 1990. - 528 p.

[14] Chinakhov D.A., Pavlov N.V., Krukov A.V. Study of experimental and theoretical temperature distribution under fusion welding // Heavy engineering. - 2010. - № 8. - P. 25-28.

[15] Chinakhov D.A., llyaschenko D.P., Pavlov N.V. Theoretical and experimental evaluation of temperature distribution in a welded unit under arc welding // Maintenance, reconstruction, modernization. - 2010. - № 9. - P. 44-47.

[16] Chinakhov D.A. Study of thermal cycle and cooling rate of steel 30ХГСА single-pass weld joints // Applied Mechanics and Materials. Vols. 52-54. - 2011. - pp. 442-447. (Online available since 2011/Mar/28 at www.scientific.net).

[17] Frolov K.V. Engineering. Encyclopedia. M.: Engineering, 2006. - 768 p.

[18] Shorshorov M.Kh., Belov V.V. Phase transformations and changes in steel properties under welding. Atlas. M.: Nauka, 1977. - 219 p. 